\title{
Den internationella underklassdebatten - vad kan vi lära?
}

\author{
SVEN-AXEL MÅNSSON
}

Med utgängspunkt frän den amerikanske sociologen

William Julius Wilsons bok The Truly Disadvantaged (1987) diskuterar Sven-Axel Månsson vilka lärdomar svensk samhällsforskning kan dra av den internationella underklassdiskussionen. En central fräga i artikeln gäller förhållandet mellan struktur och kultur iformandet av den moderna fattigdomen.

Den intensiva anglosachsiska underklassdebatten under 1980-talet var i första ett hand ett uttryck för en högervåg i politiken och avspeglade de ideologiska, politiska och ekonomiska likheterna mellan Reaganismen och Thatcherismen. Föremålet för attackerna var välfärdspolitiken, som ansågs vara den främsta orsaken till framväxten av en lättjefull och omotiverad underklass.

Att underklassbegreppet under 1990-talet börjat användas av europeiska forskare och debattörer (inte bara i England) sammanfaller främst med diskussionen om nya

Sven-Axel Månsson är professor i socialt arbete vid Göteborgs universitet. Han ingår f.n. i en grupp av forskare vid Institutionen för socialt arbete, som studerar försörjningsmönster och försörjningsstrategier bland olika befolkningsgrupper och bostadsområden i Göteborg (det s.k. Göteborgsprojektet). och sextrema" former av fattigdom och social marginalisering i storstädernas inner- och ytterområden. En del menar att utvecklingen i Europa har givit upphov till en situation som åtminstone på ytan företer stora likheter med förhållandena i de nordamerikanska storstäderna. Det talas ibland om en amerikanisering av den europeiska fattigdomen. I sökandet efter begrepp och analysmodeller för att beskriva och förstå denna utveckling har många forskares blickar kommit att vändas mot framförallt USA men även mot Storbritannien. Den upplevda konvergensen mellan amerikanska och europeiska förhällanden har aktualiserat begrepp som "ghetto» och "underklassı. Chicagoskolans socialekologiska studier av 1920och 30-talens dynamiska omvandlingsprocesser i stadsmiljö och befolkningssammansättning har återigen blivit intressanta för 


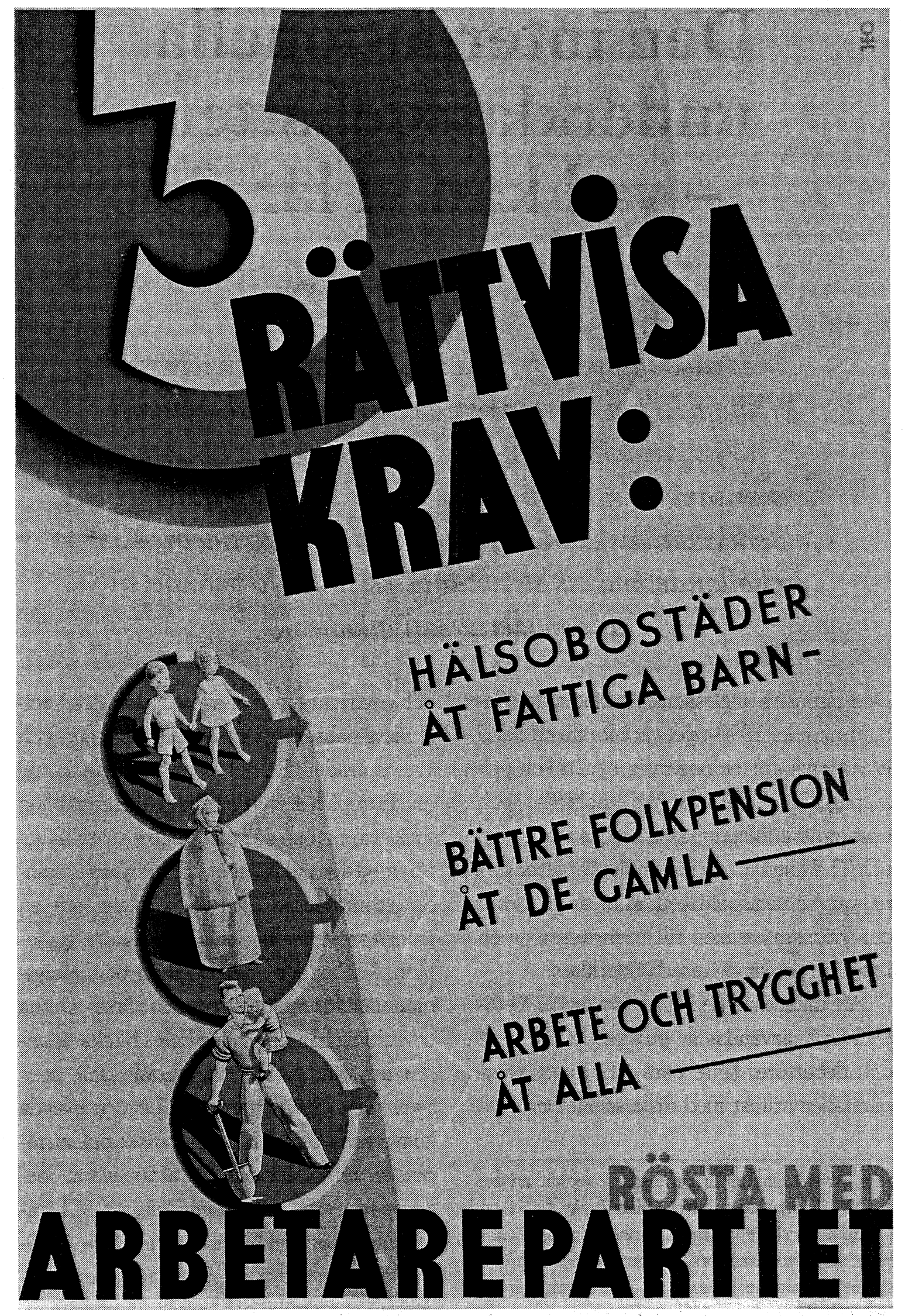

Socialvetenskaplig tidskrift nr 1-2 •96 
europeiska forskare. Denna utveckling är inte fri från kontroverser, tvärtom. På flera håll höjs kritiska röster mot att låna färdiga analytiska redskap från andra länder och miljöer - redskap vars vetenskapliga värde dessutom kommit att ifrågasättas alltmer under senare år (Wacquant, 1993).

Fattigdomsforskaren L.D. Morris hävdar t.ex. att försöken att tillämpa begreppet underklass i engelsk sociologi är misslyckade. En orsak är begreppets tvivelaktiga analytiska värde; användningen av det har visat sig medföra alltför stora förenklingar av komplexa socio-ekonomiska relationer i verkligheten. En annan orsak är att underklassbegreppet är alldeles för besmittat av den politiska retoriken för att kunna användas på ett fruktbart sätt i den vetenskapliga diskursen (Morris, 1993). Termen är, säger kritikerna, bara en modern variant av den gamla reaktionära traditionen att skilja mellan värdiga och ovärdiga fattiga. Den nya högerns definition av underklassen som ett skikt i samhället bestående av grupper och individer, som är fattiga av egen förskyllan och/eller på grund av brister i karaktär och moral, har en gång för alla diskvalificerat begreppet för användning $i$ andra sammanhang. Ett sådant patologiserande av fattigdom och utslagning skymmer sikten i forskningen, och medverkar också till att förhindra framväxten av förändringsstrategier, som bygger på de utsattas egna handlingsmöjligheter. Begreppet kan i värsta fall komma att fungera som en självuppfyllande profetia. Detta är t.ex. innebörden i Deans och Taylor-Goobys argumentation i deras inflytelserika bok $D e$ pendency Culture (1992). De hävdar att underklassbegreppet förstärker nett helt diskursivt nätverk« av negativa associationer, dvs. att de fattiga skulle vara farliga, parasitiska och omoraliska. Ett förmodat symboliskt medlemskap i en sådan »klass" kan i sig själv frambringa verkliga konsekvenser i form av konkreta identiteter och erfarenheter hos de individer och grupper i samhället, som utsätts för denna definitionsprocess. Det kan leda till apati och passivitet, men i vissa fall också rasism, högerradikalism och kriminalitet.

Men det finns de som uttrycker en helt eller åtminstone delvis annorlunda uppfattning i frågan om underklassbegreppets ställning och värde i forskning och debatt. Lảt vara, säger de, att den nya högerns version av underklassbegreppet är både stigmatiserande och vetenskapligt problematiskt. Rädslan för att använda begreppet eller att ignorera det, löser emellertid inga problem. Den nya högerns relativa framgångar i debatten har naturligtvis att göra med att man, trots ideologiska förvrängningar, har förmått tematisera reella sociala och ekonomiska problem $\mathrm{i}$ det postindustriella samhället. Begreppet har således visat sig vara effektivt för att sätta fattigdomsfrågan på den politiska dagordningen. Men alldeles oavsett vilket eller vilka begrepp som används, består den verkliga utmaningen av att åstadkomma hållbara beskrivningar och förklaringar för en politik, som gynnar individer och grupper i samhället vilka drabbats av social marginalisering och utestängning. Det är m.a.o. nödvändigt att på ett offensivt sätt ta ställning till de problem ur vilka underklassdebatten hämtar sin näring. Något förenklad kan denna argumentation sägas sammanfatta det ökade intresset för underklassfrågan bland progressiva samhällsforskare både i den anglosachsiska världen och i det kontinenta- 
la Europa (Bourdieu, Dahrendorf, Field, Gans, Mingione, Wacquant, Wilson m.fl.).

Mindre känd i Sverige, men en av de mest fascinerande forskarna på området är Chicago-sociologen William J. Wilson. Hans bok The Truly Disadvantaged - The Inner City; the Underclass, and Public Policy (1987) innehåller en av de mest vetenskapligt kontroversiella och politiskt provokativa analyserna av den svarta underklassen i USA i modern tid. Och även om Wilsons studie avser specifikt amerikanska förhållanden utgör den, enligt min uppfattning, en rik källa att ösa ur inför motsvarande studier på europeisk hemmaplan, inte minst när det gäller hans föredömligt komplexa och uppslagsrika empiriska analys av förhållandet mellan övergripande socio-ekonomiska transformationsprocesser i det nordamerikanska samhället och de konkreta vardagliga livsvillkoren i det svarta innerstadsghettot. Wilsons diskussion om fattigdomens strukturella och kulturella orsaker är också direkt användbar för en analys av invandrarnas situation i de europeiska storstäderna, dvs. av det fenomen som den franske sociologen Loïc Wacquant kallar nnew forms of urban exclusion with ethno-racial strife and segregation" (1993, s. 366).

\section{Harrington och Lewis}

Den yttersta bakgrunden till Wilsons studie måste sökas i den livliga amerikanska fattigdomsdebatten på 1960-talet. Denna debatt, som var den tändande gnistan till president Johnsons lansering av det stora kriget mot fattigdomen 1964, hämtade sin näring främst ur två källor. Den ena var motsvarigheten till "Lubbe» Nordströms
Lort-Sverige (1938), dvs. den radikale journalisten Michael Harringtons resa i det amerikanska "överflödssamhällets» hinterland, från Appalacherna via Bowery till Harlem (The Other America, 1962). Den andra var Oscar Lewis böcker om fattigdomskulturen (culture of poverty) i Mexico och Puerto Rico (1959, 1966). I båda fallen framställdes fattigdomen som ett livsmönster, "a way of life and feeling", ja närmast som en kulturell institution som reproduceras i generation efter generation. Kännetecknande för denna livsstil var också bristen på deltagande i betydelsefulla samhälleliga institutioner. Personer som lever i fattigdom skapar i liten utsträckning sina egna organisationer. Enligt Lewis har de flesta primitiva folk de facto uppnått en högre sociokulturell organisationsnivå än den moderna tidens sluminvånare. "It is crucial to generalize this idea, for it profoundly affects how one moves to destroy poverty", hävdade Harrington (a.a., s. 156). Endast en sympatiskt inställd elits interventioner kan således lyfta de fattiga ur sitt elände. Därav Harringtons vädjan efter federala insatser och därav Johnsons "war on poverty".

\section{Moynihan-rapporten}

Vid mitten av 1960-talet inträffar ett fokusskifte i den amerikanska fattigdomsdebatten. Dittills hade intresset till stora delar kretsat kring den rurala fattigdomen. Under tiden efter mordet på Kennedy börjar rasfrågan i storstäderna kräva allt större plats i den offentliga debatten. Medborgarrättsrörelsens ökade inflytande och oroligheterna $\mathrm{i}$ storstädernas ghetton var de främsta orsakerna till detta. 
Starkt medverkande till denna utveckling var också publiceringen av den s.k. Moynihan-rapporten (The Negro Family: The Case for National Action, 1965), som var en "larmrapportu om den svarta familjens förändring och upplösning. Data om stigande antal barn utom äktenskapet, tonårsaborter, ensamstående mödrar, brottsliga och drogmissbrukande fäder, massiv arbetslöshet och ett ökat bidragsberoende underströk att "the disintegration of the black family (is) one the central problems plaguing the black lower class".

Den konkreta innebörden av Moynihans demografiska material förstärktes av andra studier baserade på etnografisk fältforskning (t.ex. Kenneth Clark: Dark Ghetto , Elliot Liebow: Tally's Corner, Ulf Hannerz: Soulside m.fl.). Även skönlitterära alster av självbiografisk natur bidrog till att som aldrig förr ge offentlighet åt problemen i det svartastorstadsghettot(t.ex. Claude Brown: Manchild in the Promised Land, Piri Thomas: Down These Mean Streets).

Moynihan-rapporten orsakade en betydande kontrovers både inom vetenskapssamhället och i politiken. Rapportens beskrivningar av den svarta familjen uppfattades som stigmatiserande - känsliga frågor $\mathrm{i}$ en tid när medborgarrättsrörelsen gjorde stora framsteg. Daniel P. Moynihan väjde inte heller för att i sina konklusioner framhålla betydelsen av att de svarta erhöll reella ekonomiska och sociala möjligheter att tillgodogöra sig fördelarna med sina nyvunna medborgerliga rättigheter. Enbart nedmonteringen av den juridiska barriären löser inte problemen med ojämlikheten i levnadsvillkor mellan svarta och vita, ansåg Moynihan. Faktum är att Moynihan-kontroversen fick påtagliga konsekvenser för den amerikanska fattigdomsforskningen. I praktiken tystnade många forskare, framför allt på vänsterkanten - frågorna blev alltför ideologiskt laddade. Fortsatt diskussion och forskning med progressiva förtecken avstannade, vilket innebar att liberalerna var dåligt rustade med kunskaper och argument för att möta den högeroffensiv i underklassdebatten som skulle komma på 1980-talet.

Det är för att bryta denna liberalernas tystnad och möta högeroffensiven, som Wilson publicerar sin bok The Truly Disadvantaged. Men boken har också en förhistoria på ett mer personligt plan. Wilson hade redan 1978 publicerat en studie med titeln The Declining Significance of Race, som förorsakat mycket kritik och stämplat författaren som en exponent för den nya högern. Orsaken var - som boktiteln anger - Wilsons kritik av rasvariabeln som huvudförklaring till de svartas fattigdom. De stora klasskillnaderna mellan svarta falsifierar rasteorin, menade Wilson. Så också det faktum att tiden efter 1960-talets stora medborgarrättsframgångar hade inneburit ett snabbare socialt och ekonomiskt förfall i innerstädernas svarta områden jämfört med tiden före.

Wilsons egen tes gick således ut på att avvisa rasdiskriminering som huvudsaklig förklaring till ghettoproblemen. Visserligen, framhöll han, har en rasmässig segregation skapats genom decenniers, ja århundradens, diskriminering och fördomar (historisk diskriminering). Detta system har också placerat svarta i industrisamhällets låglönesektor. Och eftersom det är människorna i denna sektor som har drabbats hårdast av industrisamhällets kriser och omstruktureringar, så 
förstärks den rasmässiga arbetsfördelningen till de svartas nackdel. Wilson framhöll vikten av att inte kasta ut barnet med badvattnet, dvs. man behöver inte blunda för rasismen bara för att man blir medveten om att det stora problemet för fattiga svarta har med ekonomiska förhållanden snarare än med hudfärgen att göra. I The Declining Significance of Race pekade han på den svarta medelklassens sociala och ekonomiska frammarsch i både absoluta och relativa termer. Han kritiserade de ojämlika effekterna av en raspolitik som starkt gynnade den svarta medelklassen (affirmative action). Men boken innehöll också en analys av den svarta underklassen - enligt honom själv det viktigaste inslaget i rapporten men denna "glömdes bort" i stridens hetta. Som ett resultat av kritiken mot boken, bestämde sig Wilson således för att göra en ny och mer genomgripande studie, som direkt fokuserade på den växande svarta underklassens problem och att avsluta denna studie med en klar och tydlig policy-diskussion, som inte lämnade något utrymme för missförstånd. Det var alltså en påtagligt revanschsugen Wilson som gav sig i kast med den studie som nio år senare skulle publiceras under titeln The Truly Disadvantaged.

\section{Losing Ground}

När liberalerna återigen engagerar sig $i$, underklassfrågan" på 1980-talet uppstår två problem, enligt Wilson. Det första gäller villrådigheten i perspektiven. Rädslan för att underblåsa rasism och stigmatisering leder till en obenägenhet att begreppsliggöra de omfattande negativa förändringarna som inträffat i de svarta innerstadsområdena, förändringar som inte kan inordnas under en traditionell sociologisk begreppsapparat. I samma anda av missriktad välvilja finns, enligt Wilson, också en tendens att betona styrkan i det svarta lokalsamhället och den svarta familjen i stället för de tendenser till svaghet, upplösning, fattigdom och bidragsberoende, som t.ex. Moynihan hade påvisat. Det andra problemet har att göra med oförmågan att möta utmaningen från höger. Enligt Wilson utgörs högerns argumentation av en tendentiös blandning av Oscar Lewis teori om fattigdom som ett "nedärvt" kulturfenomen samt av påståenden om patologiska karaktärsbrister hos enskilda svarta. Siktet var också inställt på att misskreditera den liberalt signerade välfärdspolitiken som en av huvudorsakerna till eländet $i$ innerstäderna. Kritiken gällde de federala välfärdsprogrammen, som tillkommit under the Great Society. Reformerna ansågs ha skapat ett omfattande bidragsberoende och en utbredd defaitism bland städernas fattiga. Ökade tonårsgraviditeter och skilsmässor samt en ökning av antalet ensamförsörjande kvinnor framhölls som resultatet av en alltför generös bidragspolitik. Dessutom ansågs en alldeles för liberal kriminalpolitik ligga bakom den ökade brottsligheten och gatuvåldet.

Charles Murrays Losing Ground - American Social Policy 1950-1980 (1984) påstås ofta vara den bok som gav de konservativa de mest auktoritativa argumenten mot en liberal välfärdspolitik (Andersen och Elm Larsen, 1995). Murray hävdade att trots ökade sociala insatser under framför allt 1970- och 80-talen, fortsatte fattigdomen att öka. Han argumenterade för att välfärdspolitiken hade skapat en beroendekul- 
tur bland fattiga - bidragsarrangemangen undergrävde arbetsviljan. Enkla ekonomiska kalkyler visade att det inte lönade sig att arbeta. Unga fattiga svarta föräldrar kunde tjäna mer genom att avstå från arbete och äktenskap. Välfärd leder till familjeupplösning och dålig arbetsmoral, var Murrays slutsats. Enligt Wilson fick boken en del liberaler och forskare att vakna.

Murrays argumentation avvisades så småningom av fattigdomsforskare, som kunde belägga att förändringarna i bidragssystemet under 1980-talet hade medfört dramatiska försörjningsproblem för de fattiga. Murrays förenklade, ofta anekdotiska, exempel på de fattigas bidragsutnyttjande höll helt enkelt inte streck. Ett annat problem med Murrays kritik av välfärdsprogrammen var att han helt ignorerade de ekonomiska strukturförändringar med åtföljande massarbetslöshet som inträffade under samma tidsperiod. Förändringar som i stor utsträckning drabbade industristädernas fattiga, särskilt svarta män. Den "familjeupplösning" Murray talade om hade ofta mindre med socialbidragsarrangemangen att göra och mer med svårigheterna för svarta män i arbetsför ålder att försörja en familj. Trots felaktigheter och uppenbara kunskapsbrister firade Murrays utrerande debattstil triumfer och bidrog till politiska vinster för högern. Murrays argument har satt sina spår också $i$ andra länders välfärdsdebatt på senare år, inte minst i Sverige, där Anders Isaksson och Lorentz Lyttkens kan sägas tillhöra efterföljarna. Hans populistiska kritik var emellertid bara första etappen i högerns offensiv mot de fattiga och välfärdsprogrammen. Mot slutet av 1980-talet framträder en betydligt mer auktoritär håll- ning från den nya högern, som $i$ korthet går ut på att betona de fattigas skyldigheter mot samhället istället för deras rättigheter. Exempel på denna argumentation finns hos Lawrence M. Mead i boken Beyond Entitlement: the social obligation of citizenship (1986). Huvuduppgiften för den offentliga arbetspolitiken är att ställa krav på medborgarna/bidragstagarna att arbeta för att bryta med beroendekulturen och den "nonworking psychology“ som länge förlamat framför allt de svarta, men också andra minoritetsgrupper i storstäderna. Denna politik, som går ut mer på att kontrollera än att bekämpa fattigdomen brukar kallas workfare-i Sverige talar vi om "arbetslinjen".

Den nya högerns framfart är enligt Wilson en utmaning för forskare med liberala värderingar att föreslå bättre och empiriskt välgrundade förklaringar till innerstädernas fattigdomsproblem. I första hand handlar det om våga erkänna problemens omfattning och uttrycksformer. The Truly Disadvantaged uppfyller de kraven.

\section{Harlem då och nu}

Blacks in Harlem and in other ghetto neighborhoods did not hesitate to sleep in parks, on fire escapes, and on rooftops during hot summer nights in the 1940s and 1950s, and whites frequently visited inner-city taverns and nightclubs.

Med dessa nostalgiska rader i bokens inledning vill Wilson framhålla de djupgående förändringar som inträffat i det nordamerikanska ghettot sedan 1950-talet. De kumulativa effekterna av massarbetslöshet, familjesplittring och öppen laglöshet har förvandlat Harlem och andra liknande områ- 
den till ett annat samhälle än det som beskrivs i t.ex. St. Clair Drakes och H. R. Caytons klassiska verk Black Metropolis (1945). I detta framträder en bild av ghettot som ett vertikalt integrerat samhälle med en stark känsla av samhörighet, explicita normer och sanktioner mot kriminalitet. Men, understryker Wilson, detta var före den svarta medelklassens och arbetarklassens exodus under 1960-talet. Utflyttningen av icke fattiga från innerstadsområdena har medfört en dränering av en rad centrala ekonomiska resurser och kulturella institutioner som tidigare fungerade som en buffert mot de mest extrema verkningarna av fattigdom och utslagning.

Men utflyttningen gäller inte bara resursstarka och normgivande befolkningsgrupper, utan också industrier och arbetstillfällen. Wilson pekar på de grundläggande förändringarna i de nordamerikanska storstädernas näringsstruktur under de senaste decennierna: skiftet från varu- till tjänsteproduktion, den ökande polariseringen mellan hög- och låglönesektorer på arbetsmarknaden, flyttningen av tillverkningsindustrin till områden utanför stadskärnorna m.m. Vissa av storstäderna i landets norra delar (t.ex. New York, Chicago) har övergått från industri- och varuproduktion till att bli centra för service och informationsteknologi. Detta betyder att tillväxten sker på områden som erfordrar högre utbildning, vilket svarar dåligt mot rådande förutsättningar i de svarta befolkningsgrupperna.

Wilson urskiljer två rörelsemönster: (1) regionala förskjutningar - tillväxten inom industrin har flyttat från de norra till de södra och västra regionerna, "from the rust- belt to the sunbelt", samt (2) förskjutningar från centrum till periferi - tillväxten sker inte längre i storstädernas centrum utan i deras periferi, dvs. i förstäder och "exurbs" långt utom fysiskt räckhåll för innerstädernas fattiga.

Med utgångspunkt från Wilson menar den engelske sociologen Scott Lash (1994) att man kan tala om tre typer av senmoderna amerikanska städer:

- Avindustrialiserade städer som Cleveland, Detroit och Philadelphia, vilka inte lyckats med en framgångsrik omställning från sitt industriella förflutna.

- Omstrukturerade städer som New York och Chicago, vilka genomgått en förhållandevis lyckosam omställning.

- Postindustriella städer som Houston, Atlanta, Denver och Miami, som aldrig varit några stora industristäder. Hit kan också räknas Los Angeles, Boston och San Francisco, "äldre» städer och kunskapscentra som delvis lyckats med att skapa tillväxt inom nya områden.

Wilsons ghettounderklass finns framför allt i de avindustrialiserade och omstrukturerade städerna, inte i de postindustriella. De avindustrialiserade städerna har inga arbeten att erbjuda. I de omstrukturerade städerna finns jobb, men mest sådana som kräver högre utbildning. De jobb som inte erfordrar högre utbildning ligger, som sagt, utom fysiskt räckhåll för de fattiga. De postindustriella städerna har jämförelsevis få svarta, de har också färre »high poverty areas». Paradoxalt nog, menar Lash, finns här en omfattande arbetsmarknad med utbildningskrav som skulle passa många svarta. "Nevertheless, the relative absence of blacks in these post-industrial cities means 
that they are not there to fill the jobs for which their education level qualifies them" (Lash, 1994, s. 160).

\section{En komplex underklassteori}

Wilson förespråkar en komplex underklassteori, som inbegriper såväl demografiska förändringar som ekonomiska strukturförändringar. Som underklass betecknar han den heterogena grupp av svarta familjer och individer, som saknar utbildning och arbete, som lider av långvarig arbetslöshet eller står helt utanför arbetsmarknaden, eller som ägnar sig åt brott eller som upplever långa perioder av fattigdom och bidragsberoende. Wilson använder underklasstermen för att medvetet avbilda en verklighet som inte kan fångas med standardbegreppet »lower classu. Dessa familjer och individer delar samma predikament också it det avseendet att de bor i samma geografiska område "the ghettor. Denna rumsliga dimension har en avgörande betydelse för Wilsons socialekologiska angreppssätt.

Hans teori är till stora delar en teori om rumsliga förändringar och förskjutningar. Bidragande till förståelsen av fattigdomsutvecklingen $\mathrm{i}$ innerstäderna är den urbana och regionala omfördelningen av arbete och människor. Å ena sidan handlar det om en riktning "utu från ghettot, dvs. en accelererande dränering av arbetstillfällen, ekonomiska resurser och kulturella institutioner. $\AA$ andra sidan kan man tala om en rörelse åt andra hållet "in " mot ghettot, en rörelse med problematiska innebörder och konsekvenser, som påskyndar den nedåtgående spiralen.

Wilson exemplifierar denna senare rörel- se med den fortsatt stora migrationen av svarta till storstäderna. Drastiska förändringar i den nordamerikanska immigrationspolitiken har under 1900-talet medfört avsevärda begränsningar när det gäller inflödet av främst asiater och européer. Svarta, däremot, har fortsatt att under flera decennier strömma till storstäderna från landsbygden även om det går att skönja en viss avmattning efter 1970-talets mitt. Detta migrationsflöde är enligt Wilson en av de viktigaste förklaringarna till skillnaderna i ekonomisk framgång mellan de svarta och andra minoritetsgrupper. Genom att vara färre till antalet har nyinflyttade européer och asiater haft lättare att undgå diskriminering. De har därigenom haft större möjligheter att inmuta speciella områden för ekomomiskt entreprenörskap och avancemang.

Ett annat kritisk förändring gäller åldersstrukturen i den svarta befolkningsgruppen. Under 1980-talet ökade antalet svarta i åldrarna 14-24 år i innerstäderna med nära 80 procent jämfört med 20 procent för vita i samma åldersgrupper. Det är ett känt faktum att ju högre medianålder i en befolkningsgrupp, desto högre andel höginkomsttagare och tvärtom. »In short, much of what has gone awry in the inner city is due in part to the sheer increase in the number of young people, especially young minorities" (s. 37). Den sneda åldersfördelningen betyder större arbetslöshet, ökad kriminalitet, tonårsgraviditeter, ensamförsörjande mödrar, bidragsberoende $\mathrm{m} \mathrm{m}$.

Värst drabbade är "the public-housing projects" i storstäderna. Ett av Wilsons exempel är Robert Taylor Homes i Chicago, ett allmännyttigt bostadsområde med ca 25000 invånare. År 1980 bodde här 0,5 
procent av Chicagos mer än 3 miljoner invånare. Samma år begicks 11 procent av stadens mord, 9 procent av dess våldtäkter och 10 procent av andra våldsamma övergrepp i området. Av barnfamiljerna i Robert Taylor Homes var 93 procent ensamstående mödrar, varav nästan samtliga var bidragsberoende. Detta är en utveckling som i vissa stadsdelar bara blivit värre sedan Wilsons bok publicerades.

Ett av bokens mest omdiskuterade och kontroversiella avsnitt handlar om relationen mellan fattigdom och familjestruktur, i vilket Wilson lanserar sitt berömda "male marriageable pool index«. Syftet är att förklara den drastiskt förändrade familjestrukturen i ghettot innebärande en massiv ökning av antalet ensamstående mödrar (female-headed households). I ett antal index presenterar Wilson förhållandet mellan antalet sysselsatta män på arbetsmarknaden och antalet kvinnor i samma ålder (dvs. kvinnor på äktenskapsmarknaden). Dessa index visar en långsiktig nedgång av antalet svarta män som befinner sig i en försörjningsmässig ställning. Tendensen förvärras om man förutom arbetslösheten också tar hänsyn till den uppseendeväckande överdödligheten bland män i unga åldrar samt till den s.k. inlåsningsfrekvensen (the incarceration rate), dvs. antalet män som sitter $\mathrm{i}$ fängelse:

Kritik har framförts mot dessa index, inte minst från feministiska forskare. Implicit i Wilsons underklassbegrepp finns, enligt kritikerna, ett patriarkaliskt könsperspektiv, som innebär att han wreducerar" svarta kvinnor till äktenskapspartners och därmed förnekar deras förmåga att handla och göra val på egen hand. Svarta kvinnors faktiskt ökade deltagande i arbetskraften har skapat möjligheter att etablera en egen försörjning, om än i förhållandevis liten skala jämfört med vita kvinnor (Lash, 1994).

Hur som helst, den respektingivande och variationsrika mängd data Wilson presenterar leder alla i samma riktning. Utvecklingen är entydigt negativ för den svarta befolkningsgruppen jämfört med vita och andra invandrargrupper, möjligen med undantag för den spansktalande minoriteten. Det avgörande problemet är att alla dessa negativa tendenser verkar inom samma geografiska område, ghettot. Innebörden av detta är att fattigdomen i storstädernas innerområden får en självförstärkande effekt, när den koncentreras så extremt. Koncentrationen medför också avskiljande och isolering. Ansamlingen av sociala problem skapar en social miljö som på ett avgörande sätt skär av ghettot från det s.k. mainstream-samhället. Wilsons nyckelterm är social isolation:

The net result is that the degree of social isolation - defined in this context as the lack of contact or of sustained interaction with individuals and institutions that represent mainstream society - in these highly concentrated poverty areas has become far greater than we had previously assumed. What are the effects of this kind of social isolation? (s. 60).

Wilson besvarar själv frågan genom att framhålla den sociala isoleringens ekonomiska och kulturella konsekvenser. Isoleringen gör det svårt för dem som söker arbete att knyta an till och komma in i situationer och nätverk, där arbete finns och erbjuds. Isoleringen genererar också beteenden som de facto inte gynnar en god inställning till arbete (good work histories, regular 
habits, steady work). Kombinationen av oattraktiva arbeten och avsaknaden av samhälleliga normer som förstärker viljan att arbeta, ökar sannolikheten för att individen ska vända sig mot andra verksamheter och normsystem, företrädesvis brottslighet, gängbildning eller sysslolöshet.

Wilson pekar på framväxten av narkotikaekonomin - en av de få marknader som finns i ghettot med viss försörjningspotential. Terry Williams har studerat denna i sin bok The Cocaine Kids (1989), där han visar på de särskilda institutionella arrangemang som denna ekonomi skapar. Ett annat exempel är förstås den särskilda ghettokultur som blivit en framgångsrik försäljningsvara också utanför ghettot - rap och hiphop, street basket m.m.

\section{Wilsons bidrag - bara en ny kulturteori?}

Det kan tyckas ligga nära till hands att betrakta Wilsons teori om ghettofattigdomen som en ny kulturteori i Oscar Lewis' anda. Flera kritiker hävdar detta, dels på basis av framställningen i The Truly Disadvantaged, dels på grund av senare inlägg från Wilson (Huges, 1989; Bagguley och Mann, 1992). Kritiken går ut på att Wilsons analys bara består av en sammanställning av spridda demografiska och rumsliga data, utifrån vilka han generaliserar om individuella karaktärsdrag hos människorna i de geografiska områden, varifrån data är hämtade. Enligt kritikerna reduceras fattigdomsfrågan i Wilsons tappning till ett beteendeproblem och en kulturfråga. Fattiga svarta är fattiga därför att de är svarta och därför att de delar värderingar och attityder som förstärker deras ställning i samhällets mariginal (se diskussionen om kritiken mot Wilson hos Andersen och Elm Larsen, 1995).

Vis av erfarenheterna från sin förra bok, försöker Wilson förekomma denna kritik redan i samband med sin diskussion av begreppet social isolering i The Truly Disadvantaged. Han menar att detta klart skiljer sig från Lewis begrepp fattigdomskultur. Det senare implicerar att de grundläggande värderingarna i subkulturen har internaliserats, blivit ett karaktärsdrag i personligheten. Begreppet social isolering betyder i och för sig inte att kulturella drag är irrelevanta för att förstå beteenden i stadsdelar med en hög koncentration av fattigdom, tvärtom. Begreppet framhäver det faktum att kultur är ett svar på strukturella hinder och möjligheter. Culture of poverty, däremot, fokuserar inte på betydelsen av strukturella förhållanden, utan enbart på kulturen som ett faktum i sig. Genom att använda social isolering istället skiftas fokus från kultur till struktur, vilket är helt avgörande ur förändringssynpunkt. Den ökade sociala isoleringen i innerstäderna är en effekt av klassförändringar och sådana förändringar kan inte förstås utan att hänsyn till effekterna av fundamentala förändringar $i$ den urbana ekonomin. Så långt Wilson.

\section{Institutionellt underskott}

I en artikel från 1994 med titeln »The making of an underclassu diskuterar Scott Lash innebörderna av den dränering på ekonomiska och kulturella institutioner, som förändringarna av den urbana ekonomin har fört med sig. Avsaknaden av produktion, 
marknader för varor och tjänster, offentliga serviceinstitutioner och stabila civila institutioner som föreningar, fackliga organisationer och välfungerande familjenätverk har förvandlat ghettot till ett whyperghetto". Här lånar Lash en term från Loïc Wacquant, som menar att hyperghettot är ett ghetto präglat av ett konstant institutionellt underskott (institutional deficit). Lash menar att ett institutionellt underskott liknande det vi ser i det amerikanska hyperghettot, också kan skönjas i vissa stadsdelar och bostadsområden i. England och Tyskland. Den främsta orsaken till denna utveckling i vissa europeiska länder har att göra med välfärdsstatens ökade nedmontering och tillbakadragande av sina institutioner. På denna punkt tycker jag att man kan se Wilsons studie av de amerikanska innerstadsområdena som en väckarklocka också för svenska förhållanden. De svenska förorterna är visserligen ännu inga hyperghetton, knappast ens ghetton, om man därmed avser rumsliga enklaver strikt definierade i etniska eller rasmässiga termer. Samtidigt är de institutionella dräneringstendenserna i dessa områden ett faktum. Den pågående nedrustningen av välfärd och offentlig service i förorterna slår hårt mot de redan utsatta.

$\AA$ andra sidan kan det vara klokt att höja ett varningens finger mot ett alltför lättvindigt accepterande av konvergensteorin, dvs. teorin om ett sammanfall mellan fattigdoms- och marginaliseringsmönsterna $\mathrm{i}$ de amerikanska och europeiska storstäderna. Loïc Wacquant har i ett par uppmärksammade artiklar kritiserat föreställningen om en amerikanisering av den europeiska fattigdomen (1992, 1993). Via etnografiska jämförelser mellan Chicagos South Side och
La Courneuve, en arbetarförort utanför Paris, konstaterar Wacquant stora skillnader vad gäller de sociala och mentala strukturer som formar invånarnas vardagsvillkor och självuppfattning i respektive område. I Chicagoghettot är rastillhörigheten den helt avgörande kategorin. På denna punkt går han således helt emot Wilsons tes om rasvariabelns avtagande betydelse. "Race», säger Wacquant, nis inscribed everywhere in the ghetto: in the objectivity of space and of the separate and inferior institutions that entrap its population, and in the subjectivity. of categories of perception and judgement that its residents engage in their most routine conduct «(a.a., s. 375).

Den franska förorten är inte alls på samma sätt en rasmässigt uniform konstruktion. La Courneuve präglas istället av en etniskt heterogen befolkningsammansättning. Uppemot 40 olika nationaliteter bor i området. Den starka överrepresentationen av invandrare har främst med befolkningens klasstillhörighet och mindre med etnisk segregation på bostadsmarknaden att göra. Och den stora antagonistiska skiljelinjen i den parisiska förorten går inte mellan "svarta" och "vita", utan mellan frustrerade och marginaliserade, etniskt mixade ungdomsgäng å ena sidan och alla andra kategorier av (vuxna) invånare $i$ området å den andra. "Relations and friendship ties among the young are multi-ethnic. This does not derive from antiracist beliefs; it springs, rather, from the basic fact that, since their childhood, youths have had the same experiences in cités which are not racial ghettos"(a.a., s. 378).

Wacquants beskrivning av La Courneuve företer på flera punkter stora likheter med Paul Gilroys analyser av etniska relatio- 
ner i Storbritanniens winner-cities" (Gilroy; 1987). Likartade sociala och kulturella erfarenheter sammanför svarta och vita ungdomar med framför allt arbetarklassbakgrund i de engelska storstadsmiljöerna. Det sociala samspelet bland ungdomarna i den lokala miljön ger upphov till vad Gilroy kallar en synkretisk kultur, dvs. en dynamisk sammansmältning av olika kulturella uttrycksformer i fråga om musik, språk och kläder. En viktig kunskapskälla för Gilroy är språkforskaren Roger Hewitts (1986) ingående studier av de språkliga blandformer (the London Jamaican creole), som uppkommit genom svarta och vita ungdomars vänskapsrelationer och tvärkulturella umgänge i Londons södra stadsdelar och arbetarförorter. Hewitt framhåller »blandspråketsu identitetsskapande betydelse, han ser också dess användning som uttryck för ungdomarnas reaktion mot överhetens krav på kulturell underordning. En diskussion om liknande fenomen bland ungdomar i svenska förorter finns hos Kotsinas (1985), Ålund (1991) och Sernhede (1995). Den s.k. Rinkebyskan brukar anföras som exempel på ett blandspråk i Hewitts bemärkelse.

\section{Synkretism och underklass}

Vilken betydelse har då dessa "synkretiska kulturfenomen« när det gäller de etniska relationerna i förorten och i samhället i stort? På ett plan kan man ju säga att synkretismen representerar motsatsen till de etniska och kulturella gränsdragningar och uteslutningar, som präglar det nordamerikanska samhället. De tvärkulturella ungdomsgrupperna överbryggar och för samman i stället för att avskilja och splittra upp. Samtidigt mås- te man komma ihåg att synkretismen i första hand är just ett ungdomsfenomen. Vuxensamhället i förorten har inte samma integrativa förmåga. Tendensen bland vuxna är i stället den rakt motsatta, nämligen att förskansa sig i de egna sociala och kulturella rummen och ordningarna, som ofta är klart åtskilda från varandra och där upplevelsen av trygghet och identitet är förankrad i det förflutna snarare än i det samtida.

En annat problem med den synkretiska kulturen är att den i grund och botten bär underklasskulturens signum. Det är en kultur, där både de språkliga uttrycksformerna och musikstilarna grundar sig i en upplevelse av utanförskap och underlägsenhet i förhållande till samhället utanför. Att tala »Rinkebyska» ger visserligen en stark känsla av tillhörighet och identitet med den lokala miljön. De kreativa språkliga koderna gäckar omvärlden med sin svårbegriplighet och understryker skillnaden mellan "vi» och "dom». Men samtidigt är dessa specifika kulturella uttryck ett bevis för att man kommer från en miljö som är fattig på möjligheter och resurser. Wacquant talar om »det territoriella stigmat" som är förknippat med att vara bosatt i områden som allmänt anses vara avstjälpningsplatser för fattiga och marginaliserade grupper och individer. Att detta stigma sitter djupt i medvetandet hos de boende framgår av Wacquants och andra forskares intervjuer med invånarna i La Courneuve. Man säger sig vilja undvika att uppge sin rätta hemadress när man söker jobb, man byter språkstil när man rör sig utanför området m.m. I ett svenskt radioprogram nyligen berättade invånarna i en Stockholmsförort om liknande upplevelser och erfarenheter. 


\section{Avslutning}

Wilsons slutsats i The Truly Disadvantaged var att fattigdomen får en självförstärkande effekt när den koncentreras så extremt som den gör i de amerikanska innerstadsområdena. Koncentrationen medför också avskiljande och isolering från samhället utanför. Starkt bidragande till denna isolering är oförmågan hos samhällets institutioner att bryta fattigdomsspiralen. Från Wilson och många andra forskare vet vi att det är undermåligheten hos och ibland rentav frånvaron av institutioner som skolor, offentlig service, finansiella och kommersiella inrättningar, som är en av de viktigaste orsakerna till att underklasskulturen permanentas i ghettot. Detta är viktiga lärdomar också för förståelsen av utvecklingen i de svenska förorterna. Ett växande institutionellt tillbakadragande, med åtföljande underskott, är förmodligen det säkraste sättet att skapa en svensk förortsunderklass. Men även om ett sådant tillbakadragande inte sker, kvarstår naturligtvis frågan hur det institutionella engagemanget skall utformas för att möta och motverka de många nya problem som följer i spåren på det svenska samhällets kraftiga omvälvning. Gamla institutioner måste med all sannolikhet "tänka om" och nya strategier utvecklas. Erfarenheterna från Wilson visar att här krävs en dynamisk syn på samspelet mellan kultur och struktur. Det behövs t.ex. en öppenhet och en stödjande hållning från samhällets sida inför olika försök till etnisk självorganisering, både ekonomiskt och socialt. Samtidigt finns det naturligtvis ingen orsak att tro att ekonomiskt entreprenörskap löser den massiva arbetslösheten bland invandrare i de svenska förorterna. Men fenomenets existens utgör förmodligen ett verksamt incitament för många att knyta an till och komma in i situationer där arbete finns och erbjuds. Ett aktivt samhälleligt engagemang måste till för att stimulera en sådan utveckling och skapa arbetstillfällen, som kan möta lusten att arbeta. Den viktigaste lärdomen vi kan dra av Wilsons och andras forskning är nämligen att framväxten av en destruktiv och passiviserande underklasskultur är ett svar på strukturella hinder och på frånvaron av reella möjligheter till en rimlig försörjning.

\section{Referenser}

Andersen, John och Larsen, Jørgen Elm (1995)..Underklassen - den nye farlige klasse? « Social Kritik, vol. 6, nr. 37

Bagguley, Paul och Mann, Kirk (1992) „Idle Thieving Bastards? Scholarly Representation of the „Underclassu? "Work, Employment \& Society, vol. 6, nr. 1

Bourdieu, Pierre (1993) La misère du monde. Paris: Seuil

Brown, Claude (1966) Manchild in the Promised Land. New York: Harper and Row

Brown, Phillip och Crompton, Rosemary, red. (1994) Economic Restructuring and Social Exclusion. London: UCL Press

Clark, K B (1965) Dark Ghetto: Dilemmas of Social Power. New York: Harper and Row 
Dean, Hartley och Taylor-Gooby, Peter (1992) Dependency Culture. The explosion of a myth. London: Harvester Wheatsheaf

Drake, St C och Cayton, HR (1945) Black Metropolis: A Study of Negro Life in a Northern City. New York:Harper and Row

Gans, Herbert J (1993) From "underclassu to "undercasteu: some observations about the future of the postindustrial economy and its major victims. International Journal of Urban and Regional Research, vol. 17, nr. 3

Gilroy, Paul (1987) There Ain 't No Black in the Union Jack. London: Hutchinson

Hannerz, Ulf (1969) Soulside: Inquiries into Ghetto Culture and Community. New York: Columbia University Press

Harrington, Michael (1962) The Other America. Poverty in the United States. New York: Macmillan

Hewitt, Roger (1986) White talk black talk. Inter-racial friendship and communication amongst adolescents. Cambridge: Cambridge University Press

Huges, M A (1989) Misspeaking truth to power: A geographical perspective on the munderclassu fallacy. Economic Geography, vol. 65, nr. 10

Katz, Michael B (1989) The Undeserving Poor. From the War on Poverty to the War on Welfare. New York: Pantheon Books

Kotsinas, Ulla-Britt (1985) Invandrarsvenska och språkförändringar. Svenskans beskrivning(bil. 14). Göteborg: Göteborgs universitet

Lash, Scott (1994) The Making of an Underclass: Neo-liberalism versus Corporatism. Brown, P. och Crompton, R. (red): Economic Restructuring and Social Exclusion. London: UCL Press

Lewis, Oscar (1959) Five Families: Mexican Case Studies in the Culture of Poverty. New York: Basic Books

Lewis, Oscar (1966) La Vida: A Puerto Rican Family in the Culture of Poverty-San Juan and New York. New York: Random House

Liebow, E (1967) Tally's Corner: A Study of Negro Streetcorner Men. London: Routledge and Kegan Paul

Mead, Lawrence M (1986) Beyond Entitlement: The Social Obligations of Citizenship. New York: The Free Press.

Morris, LD (1993) Is there a British Underclass? International Journal of Urban and Regional Research, vol. $17, \mathrm{nr} 3$

Morris, L D (1994) Dangerous Classes. The Underclass and Social Citizenship. London: Routledge

Moynihan, D P (1965) The Negro Family: The Case for National Action. Washington D.C.: Office of Policy Planning and Research. U.S. Department of Labor

Murray, Charles (1984)

Losing Ground. American Social Policy, 1950-1980. New York: Basic Books

Rainwater, L och Yancey, W L, red. (1967) The Moynihan Report and the Politics of Controversy. Cambridge: MIT Press

Sernhede, Ove (1995) Modernitet, adolescens och kulturella uttryck. Göteborg: Institutionen för socialt arbete (akademisk avhandling)

Thomas, Piri (1967) Down these Mean Streets. New York: Signet Books

Wacquant, Loïc J D (1992) Banlieues francaises et ghetto noir américaine: éléments de comparison sociologique. French Politics and Society, vol. 10, nr. 4

Wacquant, Loïc J D (1993) Urban Outcasts: stigma and division in the black American Ghetto and the

French urban periphery. International Journal of Urban and Regional Research, vol. 17, nr. 3

Williams, Terry (1989) The Cocaine Kids: The Inside Story of a Teenage Drug Ring. New York: Addison-

Wesley Publishing Company

Wilson, W J (1980) The Declining Significance of Race: Blacks and Changing American Institutions. Chica-

Månsson - Den internationella underklassdebatten 
go: University of Chicago Press (andra upplagan) Wilson, W J(1987) The Truly Disadvantaged. The Inner City, the Underclass, and Public Policy. Chicago: The University of Chicago Press

Ålund, Aleksandra (1991) Lilla Juga. Etnicitet, familj och kvinnliga nätverk i kulturbrytningars tid. Stockholm: Carlssons Förlag

\section{Summary}

\section{The international underclass debate -What can vi learn?}

With a starting-point in a book by the American sociologist William Julius Wilson (The Truly Disadvantaged, 1987), the author discusses what Swedish social science and social policy can learn from the international underclass debate. One of the main issues of the article is the relationship between structure and culture in the formation of modern poverty. The author also discusses the plausibility of the notion that
European poverty is being "Americanized" using examples from international research (French and English) on the formation of immigrant ghettos in degraded working-class neighbourhoods and suburbs. The concept of institutional deficit is introduced as a way of directing attention to the role of institutions as causes for or potential remedies against a future Swedish suburban underclass. 